\title{
ENTRE A RAZÃO E A LEI SIMBÓLICA: RASTROS DE IBN ‘ARAB̄̄
}

Bia Machado (Faculdade da Imaginação)

Recibido el 16/06/2017. Aceptado el 25/09/2017.

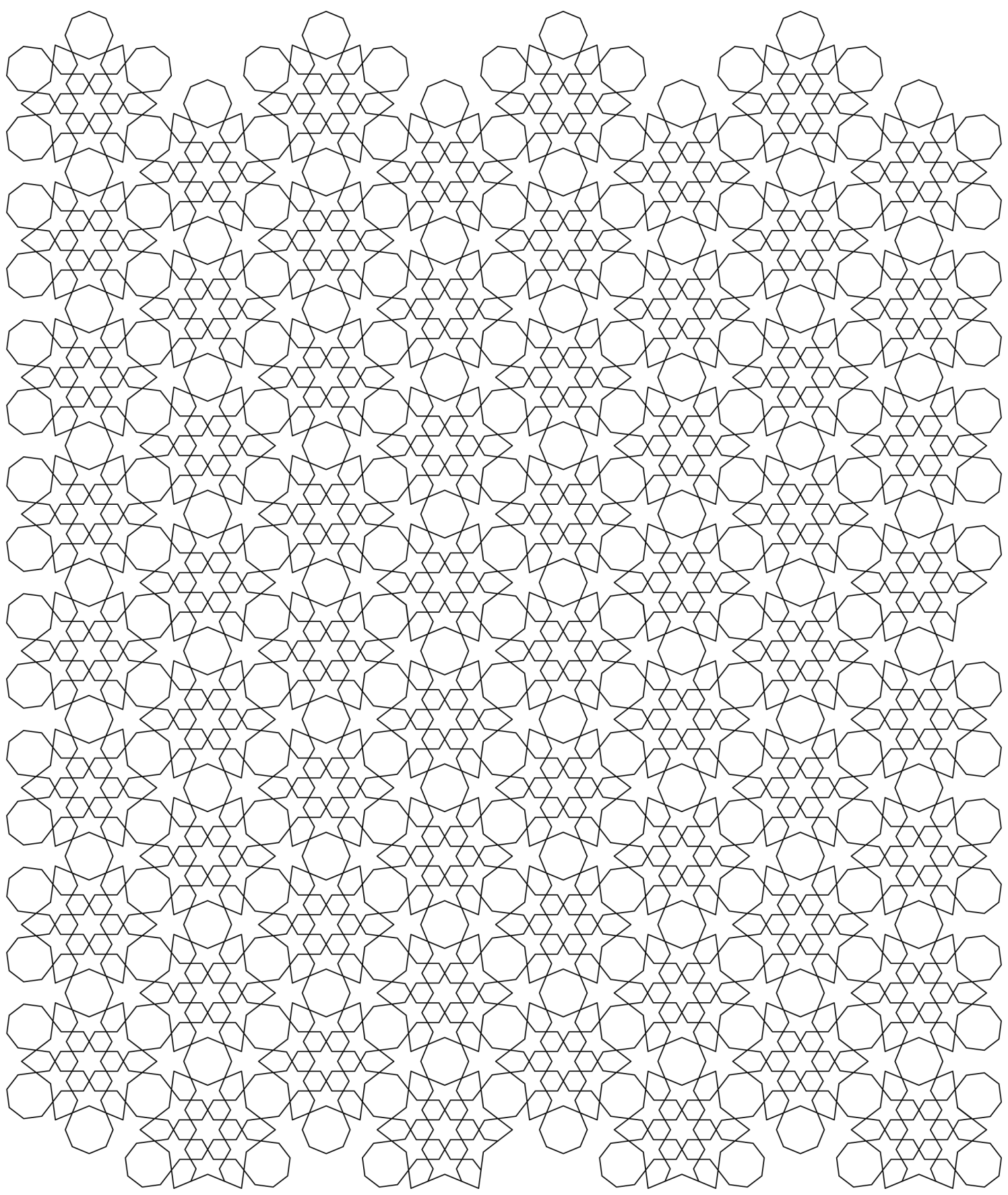


Resumo: Apropriando-me de certas formulações de Derrida, procuro fazer ver como o pensamento de Ibn 'Arabī oferece um vasto campo para a abordagem de problemas contemporâneos. A impressionante riqueza com que o Sufismo trata, por exemplo, a ideia de "escrita" e suas várias concepções de linguagem, ou os desdobramentos da relação de profunda intimidade com a revelação corânica, na qual a responsabilidade do sujeito perante o Outro-em-cada-outro é quase esmagadora, fazem dessa via mística em geral, e de Ibn 'Arabī em particular, uma trajetória indispensável para o Pensamento atual.

Palavras-chave: Derrida. Ibn 'Arabī. Interpretação. Lingua. Pensamento actual. Sufismo

Abstract: Taking advantage of certain formulations of Derrida, I try to show how Ibn 'Arabî's thought offers a vast field for approaching contemporary problems. The impressive richness with which Sufism deals, for example, with the idea of "writing" and its various conceptions of language, or the unfolding of the relationship of deep intimacy with the Quranic revelation, in which the subject's responsibility to the Other-of-each-other is almost overwhelming, make this mystical path in general, and of Ibn 'Arabī in particular, an indispensable trajectory for the current Thought.

Key words: Derrida. Ibn 'Arabī. Interpretation. Language. Current Thought. Sufism.

\section{$\therefore$}

Exatamente como num caleidoscópio, em que uma harmonia rigorosamente geométrica é sempre e inexoravelmente mantida enquanto as imagens são sempre e inexoravelmente outras a cada movimento, o Corão é ao mesmo tempo fixo e mutável.

Là tabdīla fì kalimīti Llāh, "As Palavras de Allāh não mudam", diz um verso do Livro (C.10: 64); por outro lado, suas possibilidades de significação são inesgotáveis, pois um outro verso nos diz: "Se todas as árvores da terra se tornassem cálamos, se o mar se tornasse tinta e fosse aumentado de sete outros mares, ainda assim a Palavra de Deus não se esgotaria” (C. 31: 27). Este é um dos grandes temas do Sufismo: a Revelação é sempre outra.

Muhyīddīn Ibn 'Arabī, considerado um dos maiores mestres sufis, viveu entre os séculos XII e XIII, na Espanha moura. Sua vasta obra passou a ser estudada recentemente em ambiente acadêmico não apenas pelo interesse histórico ou pela busca de conhecimento específico do Islam, mas, sobretudo, pela radicalidade de suas posições.

Claro está que o conhecimento místico opera por meio de faculdades diferentes da que habitualmente chamamos "razão", portanto, um "estudo comparativo" entre Derrida e Ibn 'Arabī, por exemplo, parece praticamente inconcebível. Não obstante, é possível utilizar o pensamento filosófico, basicamente racional, para fazer ver algumas, por assim dizer, vias de ressonância entre ambos, tarefa a que se propôs Ian Almond ${ }^{2}$.

1 Via mística islâmica.

2 Ver Sufism and Deconstruction: A comparative Study of Derrida and Ibn 'Arabi, Londres, Routledge, 2004. 
Aqui, o que proponho é seguir a via aberta por Almond e expor alguns dos principais temas de Ibn 'Arabī, fazendo ver, pela evidência mesma dos enunciados, uma espécie de "Derrida avant la lettre", ainda que essa expressão seja, a rigor, pouco derridiana; de resto, pressupor uma linearidade histórica que torne surpreendente o fato de um autor, no século XIII, dizer coisas que "só seriam pensadas séculos mais tarde" é uma tentação a ser evitada. Sem falar no fato de que a estatura da obra de Ibn 'Arabī - conhecido como al-Šayh al-akbar (o maior de todos os mestres) - torna insensato tomá-lo por qualquer outro, mesmo que esse outro seja Derrida.

A Revelação é sempre outra. Eis algumas metáforas sufis para isso: a Revelação tem a estrutura de um tapete, a urdidura - os fios que ficam presos verticalmente no tear - é fixa e invisível enquanto as tramas, isto é, o desenho, o que se vê do tapete, variam conforme a decisão de cada tecelão a cada momento. Do mesmo modo, pensemos em um navegante que utiliza o céu para navegar. As estrelas são fixas, isto é, estão acima do mar e são independentes dele, mas elas não podem, a priori, indicar ao navegante aonde ele quer ir, elas só podem dizer-lhe - a partir do momento em que ele deseja certo lugar aonde ir - por onde ir para chegar lá. Quanto mais obediente às estrelas ele for, mais seguramente chegará ao destino desejado. Sem o desejo, no entanto, as estrelas são mudas. Elas só se tornam linguagem perante este algo anterior decidido no íntimo do sujeito e cujo nome é destino. O destino, portanto, está escrito nas estrelas e, porque está escrito, não está definido nelas. Dito de outro modo, o que está escrito nas estrelas é a urdidura, a trama sendo o avesso do desejo, isto é, sua realização fictícia, sua descobridura, a flor como a mostração da semente ${ }^{3}$. E se é verdade que a flor que surje da semente estava prevista já em seu DNA, esta flor, esta aparição singular e atual, diferente de todas as outras, devemos admiti-lo, é precisamente o que não seria possível prever em momento algum desde a semente até o fim.

«As pessoas de nossa Via - que Allāh esteja satisfeito com elas! - jamais pretenderam trazer o que quer que seja de novo no que se refere à espiritualidade, mas apenas descobrir novos significados na Tradição imemorial. A legitimidade dessa atitude é confirmada por meio da palavra do Profeta, segundo a qual a inteligência de um homem só é perfeita quando ele descobre no Corão múltiplas significações [...] Ou ainda por meio da assertiva de Ibn 'Abbās: "Nenhum pássaro agita suas asas no céu sem que isto esteja inscrito no Livro de Allāh..." É por isso que cada vez que surge alguém a quem Allāh abriu o olhar interior (bașīra) e iluminou o coração, nós o vemos tirar de um versículo ou de um hadith um sentido que ninguém antes dele havia sido levado a descobrir.

3 O termo "desejo" não aparece, na Mística, com a sua acepção moderna e sua relação com uma ideia particular de destino, como mostra Marilena Chaú, em "Laços do Desejo" (in O desejo, São Paulo, Cia das Letras, 1990). O Sufismo possui variados termos, para dar conta de variadas nuances daquilo que, numa visão genérica, chamamos hoje, sobretudo na psicanálise, de desejo. Alguns termos da Mística podem ser traduzidos por "aspiração", "chamado", "vocação", "intenção", "energia espiritual" etc. 
E assim será até o levantar da Hora! Ora, tudo isso se deve ao caráter infinito da Ciência de Allāh, que deles é o Mestre e o Guia ${ }^{4} »$.

"Nenhum pássaro agita suas asas no céu sem que isto esteja inscrito no Livro de Allāh": não há nada no universo que não esteja escrito, que não seja escrita. E porque é escrita há relações de tradutibilidade entre as coisas, o universo é uma "língua", o Corão é outra, tudo o que é dito no universo é traduzível no Corão e vice-versa. A palavra árabe que podemos traduzir por "sinal" ou "signo", ayyāt, é a mesma palavra utilizada para dizer "verso", o verso corânico é idêntico ao acontecimento no mundo, ambos são sinais de Deus - āyāt Allāh.

Questão crucial é que toda tradução exige o tradutor, aquele que conhece ambas as línguas. Pensado com um sujeito agente, o homem surge como definido não por uma essência, mas por uma posição: sendo ele mesmo uma "língua" a ser traduzida, é ele quem traduz. O termo "tarğumān", traduzido adiante como "intérprete" também possui a acepção de "tradutor".

«O universo é um livro, um "grande Corão" [...]. Reciprocamente, o Livro é um universo. Falar de um é falar do outro. Entre estes dois universos - ou dois Livros - há um intermediário: o homem - trata-se, evidentemente, do insān kāmil ${ }^{5}$ - que participa da natureza de um e de outro (ele é "irmão do Corão" e é também 'alām saḡ̄r, "pequeno mundo", microcosmo). É a ele que se dirige o discurso divino sob essa dupla forma, é a ele que cabe decifrar este discurso, de ser ao mesmo tempo tarğumān al-qur'ān e tarğumān al-'alām, o intérprete do Corão e o intérprete do mundo criado, aquele que lhes dá sentido. A manifestação universal é o desdobramento dos āyāt Allāh, dos "sinais de Deus" (mas igualmente dos "versículos", tendo a palavra "āya $t "$ um e outro significado). Esses āyāt são constituídos de "palavras", kalimāt, que por sua vez são constituídas por letras, hurūf, que, num certo sentido, são as partículas elementares do Livro revelado ${ }^{6}$ ».

Mas a ideia de uma escrita "fixa", como são fixos os fios do tear ou as estrelas, não deve nos despistar. Não há uma dualidade hierarquizante entre urdidura e trama, escrita e significação, não há nada realmente "fixo".

«A existência tem sua origem no movimento. Não pode, portanto, haver imobilidade nela, pois se ela permanecesse imóvel, ela voltaria à sua origem que é o nada. [...] Os movimentos dos quatro elementos, dos seres gerados a cada minuto, a mudança e as transformações geradas por cada

4 Emir Abd el-Kader, sufi do século XIX, Écrits spirituels (kitāb al-Mawāqif), trad. M. Chodkiewicz, Paris, Éditions du Seuil, 1982 pp. 158 e 159.

5 O "Homem Perfeito".

6 Michel Chodkiewicz e outros, les illuminations de La Mecque (trechos do Futūhāt al-Makkiyya), Paris, Albin Michel, 1997, pp. 51-2. 
sopro, a viagem dos pensamentos nas categorias do louvável e do reprovável, a viagem dos sopros emitidos por aquele que respira, a viagem dos olhares, despertos ou no sono, através das coisas vistas e sua passagem de um mundo a outro pela transposição de sua significação; tudo isso é sem nenhuma dúvida viagem para qualquer homem dotado de inteligência. [...] Na realidade, não cessamos nunca de estar em viagem desde o instante de nossa concepção original e da constituição de nossos princípios físicos, ${ }^{7}$ até o infinito. Quando aparece uma morada, tu te dizes: eis o termo; mas, a partir dela, abre-se uma outra via da qual tomas um viático para uma nova partida. Assim que percebes uma morada, te dizes: eis o meu termo. Mas, nem bem chegado, não tardas a sair para retomar a estrada ${ }^{8} »$.

O homem-tradutor é, portanto, o viajante, e sua viagem é entre mundos, do microcosmos para o macrocosmos, do Livro para si, do mundo para o Livro etc. Porque seu destino está escrito nas estrelas, na urdidura, nos versos do Corão, o viajante-tradutor é aquele que utiliza a Revelação para viajar, para tecer suas tramas entre os universos, para torná-los visíveis ou legíveis. A escrita é o que nele permite a disposição da viagem, o sair de casa, o abandonar do porto; cito a frase que não é nem de Caetano, nem de Fernando Pessoa, é rastro do Encantamento ${ }^{9}$ : navegar é preciso, viver não é preciso.

\section{LUGARES DA IDEIA DE TRADUÇÃO}

A escrita não é, portanto, nem exatamente uma estrutura nem exatamente uma linguagem, embora possa ser vista como uma, como outra ou como diferente de ambas. A escrita é inteiramente plástica e inapreensível, não obstante real, concreta e atual: o verso corânico não é um significante portador de um significado, o verso é sempre outro:

«Aquele cuja compreensão é idêntica, por ocasião de duas recitações sucessivas (do Corão), é perdedor. Aquele cuja compreensão é nova a cada recitação, é ganhador. Quanto àquele que recita sem nada compreender, que Deus lhe tenha misericórdia! ${ }^{10} \gg$.

A compreensão em questão não é uma compreensão do significado no sentido moderno do termo, trata-se, na prática, de uma realização, de uma operação simbólica.

7 Usūl: deve-se compreender com este termo: os princípios de nossa constituição física, o calor, o frio, o seco, o úmido ou os da "manifestação informal", o intelecto, a alma, a matéria-prima e a natureza.

8 Ibn 'Arabī, Le dévoilement des effets du voyage (Kitāb al-isfār 'an natā'ì̆ al-asfār), ed. e trad. D. Gril, Paris, Éditions de l'éclat, 1994.

9 Mundo Encantado ou Encantamento são termos que passei a utilizar a partir da conhecida expressão de Max Weber, "desencantamento do mundo".

10 Ibn 'Arabī, cit. e trad. por Michel Chodkiewicz, em Un Océan sans rivage, Paris, Éditions du Seuil, 1992, p. 47. 
As implicações desta pequena distinção são vastíssimas, evidentemente. Faço observar apenas en passant que Ibn 'Arabī não se furta às implicações políticas deste olhar:

«Deus fez da divergência nas questões legais uma misericórdia para Seus servidores e um alargamento daquilo que Ele lhes prescreveu fazer para testemunhar sua adoração. Mas os fuqahă (doutores da lei) de nossa época proibiram e restringiram, para aqueles que os seguem, aquilo que a Lei sagrada havia ampliado em seu favor. [...] A Lei afirmou a validade do estatuto daquele que faz um esforço pessoal de interpretação para si mesmo ou para aqueles que o seguem. Mas, hoje, os fuqah $\bar{a}^{\prime}$ condenaram esse esforço pretendendo que isso conduz a uma zombaria da religião. Isto, de sua parte, é o cúmulo da ignorância ${ }^{11}{ }$.

Igualmente, é preciso atenção para a ideia de um "esforço pessoal de interpretação". Não se trata do esforço racional da ética protestante, nem da interpretação subjetiva do romantismo, experiências modernas. O termo tarğumān, que, como vimos, traduz-se por "tradutor-intérprete", conserva duas acepções que, no senso comum, dissociaram-se historicamente: de um lado, o rigor da tradução acurada; de outro, a liberdade da livre interpretação. Para não entrar, por motivos óbvios, no vasto campo dessa discussão, retomo a metáfora das estrelas fixas: o viajante obedece rigorosamente ao mapa celeste, seguindo o imprevisível desejo sem o qual o céu é silêncio. A liberdade não se opõe ao rigor, aquela é para este como a equação de Guimarães Rosa: "se não fosse a borboleta, a lagarta teria razão?"

A tradução, nesse caso, sendo um processo pelo qual uma língua se transforma em outra, trata-se de uma tradução entre urdiduras - a urdidura do Livro e a urdidura do tradutor-intérprete, o "pequeno mundo" ('alām saḡ̄r) - e a relação, portanto, só pode ser singular.

«Entre as significações possíveis de uma palavra, de um verso, não há que escolher por meio de um processo mental: o "verdadeiro" sentido - o que é verdade neste instante preciso, para este ser preciso - é o que surge, na nudeza do espírito, da letra mesma do discurso divino. É a esta letra, e a ela somente, que prestará atenção aquele cujo coração está pronto a acolher esta "chuva de estrelas" que cessará apenas no dia em que o Corão não for mais recitado "em voz alta ou em segredo" $" 12$.

A ideia de singularidade está aqui expressa por meio do termo "coração". Trata-se de um termo simbólico - portanto operativo, técnico - e não de um conceito. Para fazer ver aspectos deste simbolismo, podemos estabelecer um contexto, o que faremos por meio de uma travessia pela estrutura da língua semítica.

11 Ibn 'Arabī, cit. e trad. por Claude Addas, em La quête du soufre rouge, Paris, Gallimard,1989, p. 67.

12 Michel Chodkiewicz, Un Océan sans rivage, p. 54. 
«No árabe, diferentemente das línguas indo-europeias, a combinação das letras produz não apenas sentidos mas, sobretudo, paradigmas. As palavras são formadas por raízes, em geral, de três consoantes (encontram-se também, embora raramente, raízes de duas ou quatro consoantes). Seus diversos sentidos surgem a partir das modificações sobre a raiz, pelo acréscimo de vogais, de prefixos, sufixos etc.

Por exemplo, tome-se a palavra malik (= rei). O paradigma, isto é, a raiz, é formado pelas três consoantes MLK. Se acrescentarmos a estas consoantes as vogais "a" e "i", temos o significado "rei". Conforme alteramos as vogais, alteram-se as palavras e obtemos novos significados: malak (anjo), mulk (reino terrestre) ou malaküt (reino celeste).

Vejamos a respeito algumas considerações de Maurice Gloton. Depois de citar uma passagem do capítulo 178 do Futūhāt al-Makkiyya ${ }^{13}$, em que o mestre andaluz afirma que a "Estação do Amor" possui quatro nomes e explica os significados de cada um, Gloton passa a analisar as raízes destes nomes.

"De acordo com esta citação, pode-se obter facilmente uma profunda compreensão do significado quanto à etimologia, seja considerando uma relação de significado entre duas palavras que derivam da mesma raiz:

1) $H u b b=$ amor; Habba = grão ou semente (semente de amor). Há uma total interligação entre os dois significados: o amor produz a semente e esta germina devido ao efeito do amor contido nela.

2) 'Ašaqa = convólvulo (o que cresce numa espiral em torno de sua origem); $i s h q=$ amor crescente, espiral como uma trepadeira. Os dois sentidos também são interligados: ishq representa o Amor numa forma ascendente, de forma espiral como um dos aspectos de movimento que pertence ao Espírito $(r \bar{u} h)$ e como um convólvulo.

Seja considerando-se a polissemia da raiz de uma única palavra:

3) $W a d d=$ estaca, prego, prendedor; $W a d d=$ amor. $\mathrm{O}$ Amor designado pelo termo Wadd é sólido, enraizado e fiel.

4) Hawa = paixão; Hawā = amor. O Amor designado pela palavra Hawā é o surto do amor, a paixão de amar.

Temos aqui quatro nomes e portanto quatro diferentes conotações de

13 Uma das obras fundamentais de Ibn 'Arabī. 
Amor, embora, nas traduções, encontremos somente esta mesma palavra "amor" para todos os quatro aspectos.

Além disso, podemos destacar que o terceiro aspecto do Amor que Ibn 'Arabī qualifica de $i s ̌ q$ implica um movimento ascendente, enquanto o quarto, Hawā, também significa, no dicionário, "cair de cima para baixo" e dá origem à expressão: ar, atmosfera. Assim, a Emissão do Sopro Divino em seu duplo movimento espiral de expansão e contração, circula ou expande-se na Economia divina ou na criatura, de acordo com um movimento de ascensão e de descida como o ar aquecido pelo sol ou resfriado pela noite" 14 .

Esta polissemia das raízes é um dos motivos pelos quais cada tradução do Corão costuma aparecer com um subtítulo "tradução de alguns dos sentidos de seus versos", já que uma tradução integral seria impossível ${ }^{15}{ }$.

Além da polissemia estrutural da língua árabe, devemos também considerar o sistema ABĞAD, que consiste no estabelecimento de valores numéricos para cada letra do alfabeto. Desse modo, temos uma espécie de Cabala árabe.

Segundo o valor numérico de cada palavra, obtido pela soma das letras, é possível obter outras palavras e, assim, "revelar" outros significados implícitos:

- tomemos a palavra que designa o primeiro nome do Profeta, Muḥammad:

- as consoantes são M, H, M, M, D, e a soma equivale a:

- $(\mathrm{m}=40)+(\mathrm{h}=8)+(\mathrm{m}=40)+(\mathrm{m}=40)+(\mathrm{d}=4)=132$

- 132 é igual a $100+30+2$, ou seja, três outras letras, a saber, q=100, $1=30$ e b=2, formando a raiz qlb, que é a raiz da palavra qalb, coração.

Nesta meditação, isto é, nesta operação simbólica, todo homem que possui um coração - ou seja, todo homem - é Muhammad e, assim como o Profeta, é o receptáculo do Corão sempre novo. Ou, dito de outro modo, o coração é o órgão profético por excelência, capaz de receber o conhecimento do singular ou do atual, ou, se preferem, o conhecimento singular e atual.

O que permite a existência e a operatividade de um sistema como o ABĞAD é a compreensão da realidade como escrita.

14 M. Gloton, M., "The Quranic Inspiration of Ibn 'Arabi's Vocabulary of Love", Fournal of the Muhyiddin Ibn Arabi Society, vol. XXVII (2000), p. 42.

15 Machado, Beatriz, Sentidos do Caleidoscópio. Uma leitura da Mística a partir de Muhiyydīn Ibn 'Arabî, São Paulo, Humanitas, 2004, p. 122. 
Se, com Saussure, estabelecemos uma dualidade estrutural para a linguagem, na qual o significante veicula um significado, e essa dualidade foi desconstruída, entre outros, por Derrida, aqui, com Ibn 'Arabī, a ideia ganha uma perspectiva além, pois,

«A letra (harf) de uma coisa é sua dimensão manifesta, o "significado" (mañă) é sua dimensão não manifesta. Em síntese, "O mundo é integralmente uma letra que veio a expressar um significado. Seu significado é Deus... portanto, o significado nunca cessa de estar conectado à letra: Deus diz, 'Ele está convosco onde quer que estejais' (C. 57: 4) (Fut. III 148.10)» ${ }^{16}$.

Assim, a significação não é um processo paralelo à realidade. Ela não se refere à experiência segundo a qual alguém diz: "eu amo esta rosa" como se estas palavras em nada afetassem a realidade da rosa. Ao contrário, os processos de significação são os de realização. Dizer (e escrever) é ser, pois a vida é a Escrita.

«Perguntaram a Mālik b. Anas ${ }^{17}$ : Qual é tua opinião sobre a licitude da carne do porco d'água (hinzîr al-mā'): expressão que designa os cetáceos em geral ou, mais precisamente, os golfinhos]? Ele respondeu (fa-aftāa: trata-se de uma responsa jurídica e não de uma simples troca de réplicas) que era ilícita. Objetaram-lhe: Este animal não faz parte dos animais marinhos [literalmente "peixes" cuja carne é lícita]? - Certamente, disse. Mas, vós o chamastes de porco $($ hinz $z \bar{\imath} r){ }^{18}$.

Esta anedota nos é contada por Ibn 'Arabī para explicar o tema da ciência da nomeação (tasmiyya). Se tivessem dito "golfinho", a resposta seria que a sua carne seria lícita. Em uma perspectiva, por assim dizer, racional, o animal é o mesmo, seja ele chamado de golfinho ou de porco d'água. No entanto, nesta perspectiva, o animal não pode ser o mesmo já que o seu nome não o é, é a palavra que inaugura a realidade e não o contrário. Ou seja, não há uma linguagem, com leis próprias, e um conjunto de referentes que formam a realidade. Não há referentes, não há coisas. A realidade é a linguagem.

Tudo isso é estranho. E, para um leitor de Derrida, de certo modo, familiar. Evoco, propositalmente, a ideia de unheimlich não no sentido freudiano do termo, mas no de Schelling, tal como analisado por Bernardo Carvalho, em interessante artigo da revista Percurso ${ }^{19}$.

«Em primeiro lugar, o conceito de símbolo defendido nos textos estéticos de Schelling como modelo de produção artística ilustra exatamente esse caso de que fala Freud, quando se refere a "um símbolo (que) toma a importância e a força daquilo que era simbolizado", caso em que ocorre uma

16 W. Chittick, em Meccan Revelations I, Nova York, Pir Press, 2002, p. 241.

17 Grande jurista do seculo VIII, fundador da escola jurídica mālikí.

18 Ibn 'Arabī, cit. e trad. por Michel Chodkiewicz, em Un Océan sans rivage, p. 39.

19 Carvalho, Bernardo, "O Unheimlich em Freud e Schelling”, Revista Percurso 3, ano II, $2^{\circ}$ (Semestre 1989). 
total indiferença entre a representação e aquilo que ela representa, onde "nem o universal significa o particular, nem o particular o universal, mas fazem apenas um absolutamente".

Se para a psicanálise essa situação denota, como mostra o ensaio de Freud, uma dissolução de limites, uma ausência de delimitação do sujeito em relação ao outro, que produz necessariamente angústia e terror, para Schelling será somente com essa identificação, com essa dissolução de limites, que poderá vir à luz a realização mais alta da cultura humana: a mitologia. Esta é nada mais nada menos do que a identificação transparente do mundo da natureza com o mundo do espírito e da arte, do real com o imaginário, do natural com o sobrenatural, experimentados como um mundo único e indivisível. Ou seja, para um grego helênico, a narrativa homérica não é uma representação ou uma explicação do mundo, mas o próprio mundo.

A mitologia não é a explicação fornecida pelo espírito humano para dar conta de fenômenos incompreensíveis, de um mundo natural incompreensível, mas a própria criação desse mundo. O mundo nasce com a mitologia. Da mesma forma, uma escultura helênica de um deus não é, para os helênicos, apenas a representação desse deus, mas o próprio deus. "O que uma mitologia requer não é que seus símbolos signifiquem somente ideias, mas que sejam significantes por si mesmos, que sejam seres independentes". Nesse sentido, a definição schellinguiana de símbolo é esclarecedora: algo que é ao mesmo tempo aquilo que significa».

Claro está que o romântico Schelling encontra-se, no tempo e nas implicações, distante da perspectiva aqui estudada. Não obstante, a dissolução da separação moderna entre mito e realidade é uma aproximação mais precisa que a habitual - e imprópria - ideia de que o campo simbólico seria "a explicação fornecida pelo espírito humano para dar conta de fenômenos incompreensíveis".

\section{EGO E GORAÇÃ̃O}

«O Corão é perpetuamente novo para cada um daqueles que o recitam [...]. Mas nem todo recitador está consciente de sua descida $(n u z \bar{u} l)$ porque seu espírito está ocupado por sua condição natural. O Corão desce então sobre ele oculto atrás do véu da natureza e não resulta em gozo. É a este caso que alude o Profeta quando fala de recitadores que leem o Corão sem que este vá além de suas gargantas. Este é o Corão que desce sobre as línguas e não sobre os corações. Deus disse, ao contrário, a respeito daquele que saboreia [esta descida]: "O Espirito fiel desceu com ele [= o Corão] em teu coração" (G. 26: 193). Este é aquele a quem esta descida faz provar uma doçura incomensurável que excede qualquer gozo. Quando ele a 
experimenta, ele é [verdadeiramente] aquele sobre quem desceu o Corão sempre novo. A diferença entre esses dois tipos de descida é que, se o Corão desce ao coração, traz com ele a compreensão: o ser em questão tem o conhecimento daquilo que recita ainda que ele ignore a língua da Revelação, ele conhece o significado daquilo que recita ainda que o sentido que têm essas palavras fora do Corão lhe seja desconhecido porque elas não existem em sua própria linguagem: ele sabe o que essas palavras significam em sua recitação e no momento mesmo em que as recita. A estação do Corão e sua morada, sendo aquilo que dizemos, resulta em que cada um encontra nele aquilo a que aspira. É por esta razão que o Šayh Abū Madyan dizia: o aspirante (al-murīd) só o é verdadeiramente quando encontra no Corão tudo aquilo a que aspira. Qualquer palavra que não possua esta plenitude não é realmente Corão» ${ }^{20}$.

Façamos uma "tradução" possível desse texto. Ibn 'Arabī, como vimos, afirma expressamente que “o universo é irmão do Corão". Assim, a escrita é a revelação, isto é, a realidade. Tudo o que é real é escrita e, nesse plano, a escrita não se distingue do escrito nem do "escritor". Deus é escrita, pois o Corão "...é um atributo divino - e o atributo é inseparável daquilo que ele qualifica" "21. Ou, a existência é "uma escrita inscrita, testemunhada por aqueles que foram tornados próximos (C. 83: 20-1) mas ignorada por aqueles que não são próximos" ${ }^{22}$. Isto é, o discurso divino não é sobre a realidade, ele é a realidade. A frase inicial do texto pode, então, ser lida como: "A realidade é perpetuamente nova para cada um daqueles que a recitam/ experimentam/ conhecem / com ela entram em contato [...]"

A realidade está sempre mudando porque os tempos, os lugares e as pessoas mudam, porque, nesse sentido, há algo de único, concreto e atual a cada momento. Mas o ego não é capaz de perceber essa atualidade porque "seu espírito está ocupado por sua condição natural", isto é, o ego tende à fixidez, à repetição, aos processos identitários: "isso é uma mesa”, "eu sou assim", "defina negritude", "amor é angústia", "Derrida é filósofo", "Lacan é psicanalista".

O que é traduzir-interpretar então? É tramar, é tecer as tramas por meio da aspiração encontrada no Livro, o que se traduz sendo, portanto, as tramas do desejo. Como tradutor-intérprete, o homem é quem dá sentido aos āyāt, porém, e isso é crucial, o sentido dado pelo ego é diferente do sentido que "desce" ao coração. A interpretação egoica é racional, essencializadora e asseguradora. O ego não é capaz de perplexidade, mas o coração é. O coração é o órgão da percepção sutil23. O "sutil" é, sinteticamente falando, o aspecto "não denso", "não cristalizado" da percepção e que possui "plasticidade" e "capacidade" para assumir "todas" as formas.

20 Ibn 'Arabī, cit. e trad. por Michel Chodkiewicz, em Un Océan sans rivage, p. 46.

21 Idem.

22 Ibn 'Arabī, Meccan Revelations, p. 43.

23 Cabe observar que não há propriamente uma percepção sutil, nem um órgão de percepção sutil. Cada autor sufi, em diversas passagens diferentes, refere-se a conjuntos variáveis de "órgãos" e "percepções das sutilezas" (os latä'rif). 
E, antes que o leitor suponha que Ibn 'Arabī está estabelecendo uma dualidade hierarquizante entre o coração e o ego, deixe-me dizer que aqui não se trata de duas coisas. Ao contrário, o processo alquímico a que se referem os sufis consiste na transformação do ego em coração, trata-se, na realidade, de aspectos do mesmo campo possível.

A radicalidade desta concepção não reside na distinção entre o ego e o coração - distinção essa que é mais uma operação propiciatória que uma conceituação -, mas no modo técnico como ela se vincula a uma prática: o Livro é um lugar concreto de revelação atual. A Escrita - a realidade - é um guia de viagem real, não metafórico, não imaginário. Tudo se passa como se fosse de fato possível operar sobre o ego de modo que ele responda com suas aspirações, de modo que ele co-responda ao chamado da Palavra que lhe diz de si, de modo que ele se desvista em coração.

Nem o céu nem a terra Me contêm, mas o coração do meu servidor fiel Me contém, diz um hadith transmitido por Muhammad. O coração é este órgão "capaz de Deus" e uma das maneiras de descrever a operação (ou as múltiplas operações ao longo de uma vida) pela qual esse órgão se desenvolve reside na identificação com o Livro. O homem deve tornar-se Corão, este Outro cuja totalidade lhe permite transitar pelas totalidades de todas as coisas, que lhe faculta a percepção da realidade como tradutibilidade, imprevisto, movimento e rigor. "Perdido para aquele que parece não ligar, sinto dor, ainda que mesmo isso seja bem-vindo do Outro que exige tudo o que sou"24.

A radicalidade dessa autonomia ${ }^{25}$ - no sentido de que a Lei se torna própria pela identificação integral com a Lei simbólica, que, ao ser alteridade, não pode ser exterioridade - reside em que se tornar o Outro não é apenas uma proposta filosófica de Ibn 'Arabī, é, na perspectiva, por exemplo, do sufismo, o destino próprio de todos os homens.

\section{BIBLIOGRAFIA}

ABD EL KADER, Emir (1982), Écrits spirituels (trechos kitāb al-Mawāqiff), trad. Michel Chodkiewicz, Paris, Éditions du Seuil.

ADDAS, Claude (1989), La quête du soufre rouge, Paris, Gallimard.

ALMOND, Ian (2004), Sufism and Deconstruction - a comparative study between Ibn Arabî and Derrrida, Londres, Routledge.

CARVALHO, Bernardo (1989), "O Unheimlich em Freud e Schelling”, Revista Precurso 3, ano II, 2. Semestre.

CHAUÍ, Marilena (1990), "Laços do Desejo", in Desejo, São Paulo, Cia das Letras.

CHODKIEWICZ, Michel (1986), Le Sceau des Saints, Paris, Gallimard.

— (1992), Un Océan sans rivage, Paris, Éditions du Seuil.

24 Rumi, um dos mais importantes mestres sufis, m. século XIII. "Lost to one who seems not care,/ I feel pain, though even that is welcome/ from the Other who demands everything I am". Rumi, Unseen Rain, quatrains of Rumi, by John Moyne and Coleman Barks, p. 23.

25 Etimologicamente, se pensarmos nómos junto com Sófocles - em Antígona, por exemplo- e certa parte da tradição grega que o pensou como norma celeste. 
— (1997), Les illuminations de la Mecque, Paris, Albin Michel.

DERRIDA, Jacques (1967), A Escritura e a diferença, São Paulo, Perspectiva.

DUQUE-ESTRADA, Paulo Cesar (2002), Às Margens. Rio de Janeiro, PUC-Rio. (2002), Espectros de Derrida, Rio de Janeiro, PUG-Rio.

HADDOCK-LOBO, Rafael (2008), Derrida e o Labirinto de Inscrições, Porto Alegre, Zouk.

GLOTON, M (2000), "The Quranic Inspiration of Ibn 'Arabî's Vocabulary of Love”, fournal of the Muhyiddin Ibn Arabî Society, vol XXVII.

IBN 'ARABI, Muhyiddîn (1996), L'Interprète des Désirs (Turjumân al-Ashwâq), trad. M. Gloton, Paris, Albin Michel.

__ (1992), La Parure des Abdal (Hilyatu- l-Abdâl), trad. Michel Vâlsan, Paris, Les Éditions de l'Oeuvre. (1974), La Sagesse des Prophètes (trechos Fusûs al-Hikam), Trad. Titus Burckhardt, Paris, Albin Michel.

— (1994), Le Dévoilement des Effets du Voyage (Kitâb al isfâr 'na natâỉj al-asfâr), trad. Denis Gril, Paris, Éditions de l'Éclat.

— (1997), Les illuminations de la Mecque (trechos do Futûhât al Makkiyya), trad. M. Chodkiewicz e outros, Paris, Albin Michel.

- (2002), Meccan Revelations, Nova York, Pir Press.

LACAN, Jacques (1966), Écrits. Paris, Ed. du Seuil.

MACHADO, Beatriz (2004), Sentidos do Caleidoscópio, São Paulo, Humanitas.

RUMI (1986), Unseen Rain, quatrains of Rumi, trad. John Moyne e Coleman Barks, Nova York, Threshold Books. 